\title{
Model Eliciting Activities: An In-class Approach to Improving Interest and Persistence of Women in Engineering
}

\author{
Heidi Diefes-Dux, Deborah Follman, P.K. Imbrie, Judith Zawojewski, \\ Brenda Capobianco, and Margret Hjalmarson \\ Purdue University West Lafayette, IN
}

\begin{abstract}
A Model Eliciting Activity (MEA) is a real-world client-driven problem. The solution of an MEA requires the use of one or more mathematical or engineering concepts that are unspecified by the problem - students must make new sense of their existing knowledge and understandings to formulate a generalizable mathematical model that can be used by the client to solve the given and similar problems. An MEA creates an environment in which skills beyond mathematical abilities are valued because the focus is not on the use of prescribed equations and algorithms but on the use of a broader spectrum of skills required for effective engineering problem solving. Carefully constructed MEAs can begin to prepare students to communicate and work effectively in teams; to adopt and adapt conceptual tools; to construct, describe, and explain complex systems; and to cope with complex systems. Our conjecture is that MEAs provide a learning environment that is tailored to a more diverse population than typical engineering course experiences as they allow students with different backgrounds and values to emerge as talented. Further, we believe that adapting these types of activities to engineering courses has the potential to go beyond "filling the gaps" to "opening doors" to women in engineering. As part of an NSF funded Gender-Equity project, four MEAs were implemented in a first-year problem solving and computer tools course at Purdue University in Fall 2002. This paper will describe the nature of MEAs, overview the research methodology, and demonstrate evidence of curriculum reform at our institution.
\end{abstract}

\section{Introduction}

On the national scene, while overall enrollment and retention trends in engineering are alarming in the face of a national need to increase the technology workforce, the National Science Foundation, Division of Science Resources Statistics ${ }^{1}$ reports some gains with regards to the enrollment and retention of women in science and engineering (S\&E):

- The percentage of women enrollment in engineering programs has increased from 16 percent in 1990 to 20 percent in 1999, with the total number of women enrolled in engineering increasing despite the decline in total engineering undergraduate enrollments from 380,000 to 361,000 .

- Data suggest that women and men have nearly equivalent attrition rates with "the percentage of freshmen women intending S\&E majors in 1994 (27 percent) is close to the percentage earning S\&E bachelor's degrees in 1998 (28 percent)." 
- Of the males and females enrolled in science and engineering in academic year 1989/90 higher percentages of female than of male S\&E students completed degrees in science and engineering by 1994, and a lower percentage of female than of male S\&E students switched out of science and engineering during this time.

At Purdue University, the percent of female students completing engineering degrees has increased from nine percent (1977/78) to better than twenty percent, and has been holding at over twenty percent for the past ten years. This rate is favorable compared to national figures, where Purdue has consistently been two to three percentage points ahead of the national average ${ }^{2}$. In part, we attribute these statistics to Purdue's established history of addressing gender-equity issues through social and cultural channels. Since the 1970's, the Women in Engineering Program at Purdue University has maintained efforts to recruit and support women in the engineering program by providing a variety of services, such as support groups, special conferences, role model speakers, and outreach to middle school and high school students.

Through a three-year NSF-HRD Gender Equity in STEM grant project titled "Small Group Mathematical Modeling Approaches to Improved Gender Equity in Engineering”, we now seek to address the questions: "What more needs to be done to improve female students' interest and persistence in engineering?" and "How can we better understand the reasons that female students leave engineering despite good academic performance?" Our aim is to (1) incorporate innovations into engineering education that may be more supportive of women students and (2) research the implementation of these innovations in the education environment that is present in foundational undergraduate engineering courses. This dual focus has provided a unique way of approaching issues of gender inequity for female students in the Purdue Engineering program.

The innovation that we are implementing consists of small technical team, realistic modeling activities that address mathematical topics foundational to a number of engineering fields and address the types of knowledge and skills needed in the workplace of professional engineers. This paper will describe these activities, overview the implementation of these activities in a freshman engineering course, highlight various aspects of the research methodology, and demonstrate preliminary evidence of curriculum reform at our institution.

\section{Model Eliciting Activities}

The modeling activities that we are developing and implementing are called Model Eliciting Activities (MEA). These are client-driven real-world problems that are developed using the six principles of design shown in Table $1^{3,4}$.

Solutions to the MEAs we are developing require the use of one or more mathematical or engineering concepts that are unspecified by the problem description-students must make new sense of their existing knowledge and understandings to formulate a generalizable mathematical model that can be used by the client (customer or end-user of the solution) to solve the given and similar problems ${ }^{5}$. An MEA creates an environment in which skills beyond mathematical abilities (e.g. communication, verbalization, and an ability to work cooperatively and collaboratively ${ }^{6}$ ) are valued because the focus is not on the use of prescribed equations and algorithms but on the use of a broader spectrum of skills required for effective engineering 
problem solving. Carefully constructed MEAs can begin to prepare students to communicate and work effectively in teams; to adopt and adapt conceptual tools; to construct, describe, and explain complex systems; and cope with complex systems. Carefully selected engineering contexts (e.g. client and engineering application) can stimulate the interest and involvement of a more diverse student population ${ }^{7,8}$. Further, the attributes of MEAs support the development of the abilities and skills required of graduates of accredited engineering programs as stated in ABET Criterion 3 a to $\mathrm{k}^{9}$.

Table 1. Principles for guiding MEA development ${ }^{3,4}$.

\begin{tabular}{|c|l|}
\hline Principle & \multicolumn{1}{c|}{ Description } \\
\hline Model-Construction & $\begin{array}{l}\text { Ensures the activity requires the construction of an explicit description, } \\
\text { explanation, or procedure for a mathematically significant situation }\end{array}$ \\
\hline Reality & $\begin{array}{l}\text { Requires the activity to be posed in a realistic engineering context and to } \\
\text { be designed so that the students can interpret the activity meaningfully } \\
\text { from their different levels of mathematical ability and general knowledge }\end{array}$ \\
\hline Model-Documentation & $\begin{array}{l}\text { Ensures that the activity contains criteria the students can identify and } \\
\text { use to test and revise their current ways of thinking }\end{array}$ \\
$\begin{array}{l}\text { Ensures that the students are required to create some form of } \\
\text { documentation that will reveal explicitly how they are thinking about the } \\
\text { problem situation }\end{array}$ \\
\hline $\begin{array}{c}\text { Construct Share-Ability } \\
\text { and Re-Usability }\end{array}$ & $\begin{array}{l}\text { Requires students to produce solutions that are shareable with others and } \\
\text { modifiable for other engineering situations }\end{array}$ \\
\hline Effective Prototype & $\begin{array}{l}\text { Ensures that the model produced will be as simple as possible yet still } \\
\text { mathematically significant for engineering purposes }\end{array}$ \\
\hline
\end{tabular}

The principles for designing MEAs have been developed, tested, and refined by hundreds of teachers working collaboratively in a series of NSF-supported state or urban systemic initiatives $^{3,10}$, and the successful implementation of MEAs in K-12 has been remarkable ${ }^{11}$. Modeling activities exist in every undergraduate engineering curriculum though they may or may not adhere to the principles of MEA design. Through the development and implementation of MEAs with engineering contexts, we seek to tie the design of the MEAs to the promotion and enhancement of gender equity and the success and confidence of women students in engineering.

III. Implementation of MEAs in a Freshman Engineering Course

ENGR 106: Engineering Problem Solving and Computer Tools is a required 2-credit hour course for all freshman engineering students at Purdue University. This course is designed to give students an appreciation for what the pursuit of an engineering degree entails. The course learning objectives are such that students successfully completing the course are able to:

- Develop a logical problem solving process which includes sequential structures, conditional structures, and repetition structures for fundamental engineering problems,

- Translate a written problem statement into a mathematical model,

- Solve fundamental engineering problems using computer tools,

- Perform basic file management tasks using an appropriate computer tool,

- Work effectively and ethically as a member of a technical team, and

- Develop a work ethic appropriate for the engineering profession. 
The syllabus is a coordinated mix of introduction to engineering fundamentals, including graphical representation, statistics, and economics, and introduction to computer tools used to solve engineering problems, specifically MATLAB (a computational tool and interpreted programming language used by engineers), Excel, and UNIX. The course consists of two 50minute lectures and one 2-hour computer laboratory period per week. The lectures focus on fundamental engineering concepts and problem solving. Prior to Fall 2002, each lab period was organized into a series of four or five tasks to be completed either by teams of four students or individual students, as specified by the instructors. Typically, tasks provided the students with structured exploration of the use of new computer tool syntax/procedures and simple fundamental engineering problems. Each lab concluded with a "check for understanding" on the new concepts covered in the lab. Students then applied the theory introduced in lecture and the syntax/procedures learned in lab to the solution of homework problems and team projects with engineering context.

In Fall 2002, four MEAs were included in ENGR 106. Each MEA consisted of a lab component, a homework component, and, in one instance, a project component. In the lab setting, students worked for the first 45 minutes in teams of four on an initial model-eliciting activity. For each MEA, students read background material about the problem and then discussed guiding questions on their team's private WebCT discussion board*. During the entire lab activity, students were asked to complete the activity in real time on-line rather than in face-to-face interactions. At the start of each MEA, students were reminded that the purpose was to simulate a work place environment, where members of a problem solving team may be located in geographically diverse sites. In addition, students were provided with a list of guidelines for completing the MEA and general use of the discussion boards. Teaching Assistants (TA) were instructed to not provide assistance in solving the MEAs as we did not want the students to be guided down the TA's solution path.

The decision to eliminate face-to-face interactions in the lab was made for both pedagogical and practical reasons. First, this type of experience would help prepare students to work on teams of engineers in the real workplace who are located in different places around the country. So by using the WebCT discussion boards, we, in essence, were able to simulate the situation where a team of engineers with members from all over the world meet simultaneously to complete engineering related tasks. Second, the literature suggests that women (and others of diverse backgrounds) may be able to take on more leadership roles, have their ideas survive, and participate more in electronic teaming environments compared to when they work with their team members face-to-face. According to Seymour and Hewitt, the competitive classroom environment was one reason that students may decide to switch out of engineering ${ }^{13}$. In addition, women in the Seymour and Hewitt study reported that men in their laboratories sometimes assumed they were incompetent and proceeded to take charge of the group or provide unnecessary help. Such assumptions may impact how students work together in face-to-face situations. Margolis and Fisher support diverse pedagogical methods that would allow for a change in classroom culture ${ }^{8}$. In order to increase women's perseverance and persistence in engineering, electronic teaming environments may allow for a more diverse set of learning styles

\footnotetext{
* All ENGR 106 course information and materials are delivered and managed using WebCT Campus Edition. WebCT is an online course management system that provides a number of teaching and learning tools for course development, course delivery, and course management ${ }^{12}$.
} 
as well as increasing women's opportunities for participation and communication within the team $^{14}$.

From a practical standpoint, using the WebCT discussion board capability enabled more efficient data collection and analysis, since the student conversations would be documented - saving the time and expense of transcription.

\section{Four Model-Eliciting Activities}

Below are descriptions of each of the four MEAs used in ENGR 106 in Fall 2002. For each MEA, the placement in the semester is indicated with the connection to the course content.

Laser Detection Devise Design. This MEA was implemented in the third week of the semester. It draws on students' prerequisite mathematics skills. The homework component required the students to develop their first substantial MATLAB script in which they assign variables, use algebra and trigonometric functions, and display computational results.

Lab Component: Students read a brief story about use of laser surveillance in theft prevention. The story describes the relationship of the laser beam transmitter and the receiver and how the use of mirrors can be used to minimize the number of transmitters and receivers needed to survey an unusual-shaped room or a room with large supporting columns. The students were then provided with the layout of two rooms in which art is displayed and must be monitored using a rotating transmitter placed in one corner of the room and receivers placed by the art objects. One room used a simple configuration where there are no obstructions between the transmitter and the receivers at each art object (Figure 1). The second room required a mirror placed along one wall as some art objects obstructed the laser beam's access to the receivers on another objects. Students were asked to apply their knowledge of basic high school level algebra and trigonometry to answer a series of questions. With regards to the first room, the students were asked:

a. How can you consistently and quantitatively describe the location of the objects and the transmitter? That is, how can you use numbers to describe the exact location of the objects and the transmitter in the room?

b. How will you consistently and quantitatively describe the position of the transmitter (and thus the trajectory of the laser beam) relative to its home position?

c. How will you calculate the positions of the transmitter?

With regards to the second room, the students were asked:

a. How will you consistently and quantitatively define the angles of the transmitted laser beam, reflected laser beam, and the beam as received at the object?

b. For a given laser beam, how are these angles related to each other (e.g., complementary, supplementary, congruent).

c. How will you calculate the positions of the transmitter for cases where you reflect the beam off the mirror? 


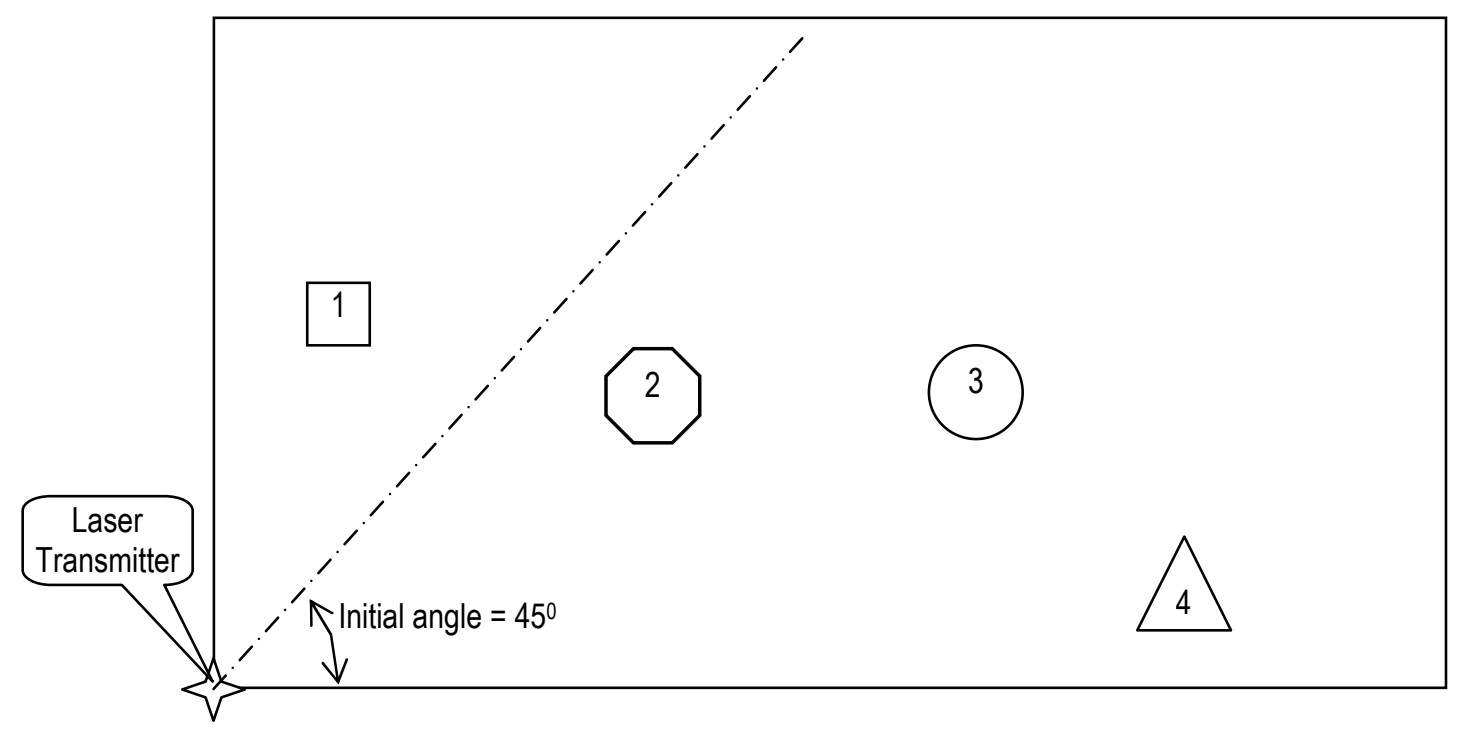

Figure 1. Simple art gallery room with laser surveillance.

Homework Component: Students were provided with a more complex art gallery room configuration in which the art cases were set against supporting columns in the room. Based on the placement of the columns, either the columns or the art objects could obstruct the laser beam's access to various receivers, thus requiring mirrors. Students were asked to develop a model to compute the laser beam's position relative to the home position given the location of the receivers. Their final product was a MATLAB program.

Banking Options. This MEA was implemented in week six. Students had begun studying timevalue of money the previous week. Students were expected to use their knowledge of simple economic relationships in the design of their first relatively complex spreadsheet.

Lab Component: Students were introduced to three types of investment strategies that families can use to plan for college tuition costs: fixed rate investments, mutual funds and stocks, and money market funds. The client is an investment firm that wishes to develop a spreadsheet that families can use to determine how much they need to invest each month or each year based on their income and the tuition costs. For the first part of the task, students were posed guided questions to orient them to the design of the spreadsheet. For instance, they were asked:

a. What variables should a family consider when planning an investment strategy for college?

b. Who will be the users of the spreadsheet your team will develop for the investment firm?

c. What questions should the user be able to answer when using this spreadsheet?

d. What pieces of information (values) should the users supply to the spreadsheet?

For the second part of the task, each team member independently developed an Excel spreadsheet to predict the cost of tuition in the future. The team then evaluated each other's spreadsheets for usability in solving a test case.

Homework Component: Students created a spreadsheet for the investment firm that can help families determine how best to invest their money in different types of fixed rate accounts to 
save for college. Students were provided with information about various CDs, savings, and money market accounts. Students were asked to design the spreadsheet such that it included at least two completely different types of investments to allow the family flexibility in managing their money.

Departing on Time. Students completed this MEA in week nine following two weeks of introduction to statistical concepts including data characteristics, histograms, and cumulative distribution plots. Students were allowed to decide whether to develop their model in Excel or MATLAB.

Lab Component: Students were given departure data for a number of airlines. The task was to help a high school Spanish Club determine which airline has the smallest chance of departing late so a connecting flight can be made. Students were asked to address the following questions:

- What criteria will your team use to rank the airlines?

- How will your team use the historical data to develop a procedure for ranking the airlines in terms of most likely to be on time to depart?

Homework Component: Students were provided with historical departure time data for five airlines on which to perform their analysis. The final product was a letter to the Spanish Club indicating a ranking of the airlines and detailing a procedure for determining the ranking, should the Spanish Club need to perform this analysis again in the future.

Aluminum Crystal Size. The lab component of this MEA was completed in week 10 and kicked off a six-week team project. To adapt the mathematical model, the students applied the MATLAB programming skills acquired throughout the semester.

\section{Lab Component:}

This activity required students to develop a procedure to measure crystal size, given micrographs of three different samples of aluminum. A micrograph is a microscopic photograph of a metal sample that has been polished to produce a smooth flat surface and then etched to highlight the boundaries between crystals/grains (e.g. Figure 2). The motivation for developing the procedure was established by using a realistic context in which

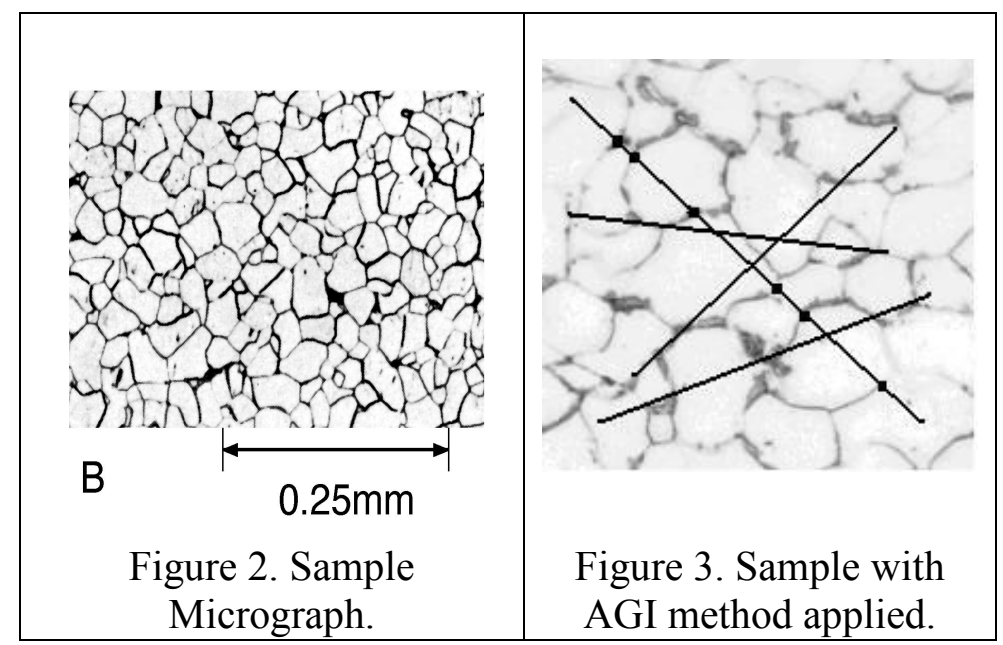

Figure 2. Sample Micrograph.
AGI method applied.

an aluminum baseball bat producer wants to improve quality control by monitoring the crystal size (an indicator of strength) of aluminum samples. Student teams of four were required to create a procedure for measuring crystal size given micrographs with variable scales and nonuniform crystal size within any sample. The students then applied their procedure to the three different micrograph samples. 
Homework Component: Students learned about the average grain intercept (AGI) method. This is a technique used by engineers to quantify the grain - or crystal - size for a given material by drawing a set of randomly positioned line segments on the micrograph, counting the number of times each line segment intersects a grain boundary, and finding the ratio of line length to number of intercepts (Figure 3). Student teams compared their method to the AGI method by: (1) discussing the similarities and differences between the methods, (2) using both methods to determine the average crystal size for three aluminum micrographs, and (3) indicating the ways in which the AGI method lends itself to the development of a software tool.

Project Component: Students learned that a digitization of a micrograph can be stored as a data file which contains an array of numbers where each number refers to the gray scale value for each pixel of the micrograph. Student teams used this information to implement the AGI Method using MATLAB. This project allowed students to put into practice their knowledge of flow charting, user-defined functions, repetition and flow control structures, 2-dimensional array manipulations, and reliability considerations (statistics).

\section{Research Methodology}

The primary purpose of our research was to examine carefully the implementation of the MEA's and its impact on students' interest and persistence in engineering. Both qualitative and quantitative methodologies were employed to gather preliminary feedback from students and faculty. These methodologies included surveys, semi-structured interviews, and document review.

\section{Student and Teaching Assistant Surveys}

Student Lab Reflections: Starting with the second MEA of the semester, all students enrolled in ENGR 106 were assigned Lab Reflections to complete following MEA and content-related traditional labs. In total, six lab reflections (three concerning labs with MEAs and three without) were completed. The research team did not assign a Lab Reflection following the first MEA because it was felt that students would not have sufficient familiarity with the MEA and traditional lab formats or the teaming aspect of the course to answer the reflection questions effectively.

Likert scale items were used to collect data on students' perceptions of (1) their interest and persistence in completing the lab tasks, (2) whether the lab tasks represented things they believe engineers do, and (3) the teaming experience, the team's functionality, and their ability to work with, learn from, and contribute to their team. For the labs with MEAs, an additional set of questions was targeted at students' perceptions of the WebCT interaction and developing a solution for a client. The students were also asked open-ended questions about what they liked/disliked and could be improved about the particular lab. Data analysis focuses on gender, ethnic, and team composition differences.

Teaching Assistant Surveys: At the end of the Fall 2002 semester, both the graduate and undergraduate Teaching Assistants (TAs) completed a survey focused on their perceptions of students' interest and persistence in MEA and traditional labs. In addition, the TAs were asked 
to state what they liked/disliked and could be improved about both types of labs. The TAs were the sole instructors in the lab setting. As such, they have a tremendous impact on the way MEAs are conducted, and they have first-hand knowledge of students' behavior and attitudes during lab. Therefore, the purpose of the surveys was to gather formative feedback about the implementation of the MEAs in comparison to traditional labs.

\section{Student Interviews}

During Fall 2002, a recruitment plan for student interviews was developed and implemented. First-year engineering students indicating that their intended engineering major was mechanical or material science engineering were contacted by phone. These majors were targeted because MEA implementation was planned as part of this project for continuation in select sophomore level courses. Students were given an overview of the project. Volunteers signed a consent form indicating that participation was voluntary and told that their participation would not impact their final ENGR 106 course grade. Forty students indicated interest in participating. Of the forty interested participants, 24 freshmen engineering students agreed to participate and were interviewed from November 2002 to January 2003.

During the Fall 2002, twenty-four freshmen engineering students were interviewed. The students included: 11 males (1 Hispanic/Latino; 3 Asian American; 7 Caucasian) and 13 females (1 Latina; 1 Asian American; 10 Caucasian; 1 "other multi"). The main goals of the semi-structured interviews were to:

- gather preliminary feedback from the students about their reactions to and engagement in the MEA's as well as their interactions within technical teams;

- examine gender-related patterns for levels of interest, persistence, and possible resistance as well as expectations for future career paths in engineering; and

- pilot the interview protocol and determine its effectiveness at gathering student feedback, thereby informing the second implementation in the project.

To measure long term impact on students' interest and persistence in engineering, we conducted follow up interviews with a smaller cohort from the original 24 students as they entered their sophomore year. In the fall 2003, we contacted the original 24 students by email and phone, and invited them to participate in a follow up interview. Eighteen of the 24 students agreed to participate and were interviewed from November 2003 to December 2003.

\section{Faculty Interviews}

A recent edition to the research methodology was faculty interviews. As this study progressed, we observed changes in the ways the engineering faculty talked about using the MEAs in their own teaching practice. We decided it was important to capture how the instructors were modifying curriculum, integrating the MEAs, and reflecting on students' performance. We wanted to learn first-hand how the instructors envisioned and enacted curriculum reform by using the MEAs to increase young women's interest and persistence in the engineering program. Two professors - one freshman engineering professor (Caucasian female) and one mechanical engineer professor (Caucasian male) - were identified as key informants. These two faculty lead the implementation of MEAs in target freshman and sophomore courses and were new to MEA development prior to the start of this project. Each professor was interviewed on three separate occasions; at the beginning, middle, and end of the Fall 2003 semester. Emphasis was placed on 
interviewing each instructor before and after the integration of at least one MEA. Analysis of this data set is currently underway.

\section{Document Review}

Documents that are under review include student work on labs, homework assignments, and the project. Much of the analysis to date has focused on the WebCT discussion boards. We are investigating the types of interactions in which students engage as they solve MEAs in teams of four. Transcripts of the discussion boards of twenty ENGR 106 student teams collaboratively solving MEAs online have been examined. We have employed both qualitative research techniques and a theoretical framework to provide descriptions of the types of roles (e.g. facilitator, critic, validator) students adopt on teams and the styles (e.g. authoritative, collaborative) with which they enact their roles. We are making a comparison of the frequencies with which male and female engineering students adopt certain roles or styles and the effects of the roles and styles on the flow of ideas and power within the student teams. We are also looking at the effect of group composition on these findings. The results of this study will provide insight on how to better teach teaming and diversity awareness, assign student teams, and assess "effective" teamwork.

\section{Data Analysis}

Data analysis of qualitative data (i.e. student and faculty interviews, student work, and openended survey items) was conducted via open coding ${ }^{15}$. We marked segments of data by attaching code words (abbreviation of key words) to those segments, and retrieved all segments identified by the same code or by a combination of code words. Examples of codes generated from student interview data included "RW-APP" and "PRAC-EXP". These codes indicated that students associated the MEA's as providing "real world appeal" or "practical experiences." We then organized and re-organized our segments of coded data into categories. To determine the plausibility of our categories, we employed the process of peer debriefing whereby we consulted with other members of the research team. These consulting sessions allowed us to uncover patterns and emerging themes within each respective data set. One theme that developed from student interview data was "contextualizing engineering". This theme describes the ways the MEA's facilitated interest among students and how MEA's allowed students to understand principles of engineering by placing them in the context of real world applications and practical experiences.

\section{Initial Evidence of Reform}

\section{Professional Development of Faculty}

This has been a highly collaborative effort between faculty of the Schools of Engineering and Education. Education of the project staff has taken place in an implicit manner during development and implemention of the MEAs and ongoing discussion about gender equity issues as this curriculum reform is investigated. While one would expect a great deal of professional development for graduate students, the professional development among the faculty has been remarkable. Each faculty group brought different perspectives, expertise, and literature from their field to the project. Each faculty member has grappled with and gained a great deal of new knowledge and understanding from the interactions among the various faculty groups. 
The education faculty contributed expertise in teaching and learning mathematics in grades K12 , and an understanding of how gender equity issues emerge in school mathematics and science, and in society. The education faculty provided a modeling perspective on the design of activities that would tap women's strengths, by encouraging learning through problem solving in rich contexts involving clients with clearly specified needs. They also brought an understanding of the theory and research underlying small group learning, which can inform the use of team problem solving in the engineering courses. The education faculty have a tradition of using qualitative research methods, that have grown out of the areas of anthropology and social science research. Working to understand why and what students learn, believe, and do requires an interpretative perspective on research and is the crux of knowledge attainment in the education field.

The freshman engineering faculty have expertise in particular fields of engineering, an understanding of the expectations the Accreditation Board for Engineering and Technology (ABET) has for engineering graduates, experience teaching and designing introductory freshman engineering courses (e.g. ENGR 106), and knowledge of Purdue freshman engineering student characteristics. For example, the freshman engineering faculty understand the challenges students face as they transition from being "top students" in their high school classes to one of many "top students" enrolled in a Research I engineering program. The faculty also understand the challenges students face as they make a transition from high school courses, which are largely concerned with coverage of content for the purpose of performance on state testing, to university class work that more closely resembles the work of practicing engineers. These engineering faculty also have a deep concern for optimizing experiences and opportunities for women and minority student in the engineering program but recognize the need to simultaneously meet diverse expectations for the freshman program (e.g., expectations of students about what the course and program should be, expectations of upper-level engineering course professors about preparation).

The variety of perspectives, combined with the collaborative stance of all project staff, has provided continual opportunities for faculty to learn from one another as they work to develop new course materials, implement curriculum reform, and document, evaluate, and understand what is happening in this curriculum reform effort at Purdue University.

\section{Changes in the ENGR 106 Curriculum}

One goal of the ENGR 106 course is for students to learning to use MATLAB, Excel, and UNIX to solve fundamental engineering problems. However, as a freshman engineering course, another goal is for students to learn about what it is that engineers do and how they work in the world. One change that MEA implementation has brought about is a shift in the course focus from a long list of small, discrete technological skills (e.g. writing a "for" loop in MATLAB) to a smaller list of larger ideas (e.g., designing an algorithm) that get at the core of what it means to be an engineer who uses technological tools to solve real-world engineering problems. Learning the specific technical skills is still important, but it can now be situated within what it means to do engineering work. However, once we began looking at the course as an introduction to authentic engineering work, we had to evaluate what it means to "do engineering" and how those ideas can be introduced to freshman engineers. From a curriculum design perspective a tension arises when selecting contexts for the MEAs. The contexts must be complex enough to allow for 
the generation of models but simple enough that students without an engineering background can apply the knowledge and experience they do have to the problem solution.

The contextualization of technical content is one of the most important issues in this research. One reason women cite for leaving $\mathrm{S} \& \mathrm{E}$ is that the content does not seem relevant or related to their interests or the real world ${ }^{8,13}$. The other type of curriculum shift in the ENGR 106 course is toward contextualization of technology within authentic engineering contexts. So, rather than learning about technology for technology's sake, students are learning how technological tools can be applied by engineers in the workplace. Margolis and Fisher found that using context to drive the need for technological tools significantly increased women's persistence in computer science $^{8}$. Imbedding content and technology in real-world contexts via implementation of MEAs in engineering courses should increase the relevance of coursework to all students but particularly female students.

As we develop MEAs for subsequent semesters, we are looking at the diversity of contexts in which engineers are valued and at how students versus engineers define engineering. Many freshmen enter engineering without a clear idea of what it is that engineers do or the types of issues that require or affect engineering decisions. We are bringing contexts into the classroom that students may not have realized were engineering. For example, first-year students probably know that engineers design cars and bridges, but they may not know that engineers also design materials. Note that the content and context for the Aluminum Crystal Size MEA came from materials engineering. Currently, we are developing MEAs that address some of the societal, ethical, environmental, or cultural factors that impact engineering problem solving - problem contexts that support women's interest in engineering ${ }^{16}$. The introduction of unfamiliar or emerging areas of engineering should not only expose all students to the variety of fields where engineers work, but also increase women's perseverance in engineering since these are contexts identified as particularly appealing to women's interests in being engineers ${ }^{7,8}$.

While analysis of the Fall 2002 is still ongoing, preliminary findings indicated that the inclusion of the MEAs in ENGR 106 was valued by the students, the teaching assistants, and the faculty for their exposure to real-world engineering problems. However, concerns over a number of implementation issues were consistently expressed.

Faculty needed to be involved in presenting the MEAs to the students. A disconnect occurred between the labs, where the TAs are primarily responsible for instruction, and the lecture, where the faculty are responsible for the instruction. In Fall 2003, students worked through one MEA in the lecture setting, and the faculty walked the students through the purpose of MEAs and their expectations of student and team performance.

Since TAs are on the 'front line' in dealing with freshman students' reactions to these tasks, their buy-in and training is critical. In Fall 2002, one training session introduced the TAs to MEAs. The purpose was to help the TAs see the value of incorporating these types of activities into the engineering curriculum. It also provided an opportunity for the TAs to experience doing one of the activities. A number of TAs had taught or taken ENGR 106 in previous semesters and were, in some cases, very resistant to the change. It was of concern that this negatively affected their students' perceptions of the lab activities. In Fall 2003, a more rigorous training program was 
developed with the aim of engaging the TAs in the MEA development and implementation process. Before classes began, TAs not only experienced the first MEA they would use, they were instructed on the design principles of MEAs, how the MEAs link to the course learning objectives, and how they should interact with the student teams during an MEA. Over the course of the semester, the TAs worked through each MEA in teams and provided feedback to the research staff before the MEAs were used in their classrooms.

One of our goals was to provide an authentic engineering work environment in the lab setting. However, the WebCT discussion boards hindered rather than helped in meeting this goal. Students - who were actually in the same room - were frustrated that they could not simply talk to team members when there were substantial delays in the 'real time' on-line discourse. The use of WebCT did not actually enable synchronous interaction, and therefore, provided a poor environment for engagement in the model-eliciting activities. A new on-line interface was developed for Fall 2003 that capture student's initial thoughts about the problem and the team's final solution to the lab component of the problem. This interface allows the TAs to provide the students feedback on their work before they complete the associated homework component. While we have lost our ability to capture details of the discourse, we felt a more natural interaction among students would ease their frustration.

In addition, we realized that for students to work on a complex engineering task, we needed to allocate more time than originally anticipated in lab to complete the tasks. In complex problem solving, the first idea is not always the best idea, so students needed more time in lab to work with their teams to consider multiple perspectives and multiple solutions and communicate their method to the client in the task. The content of ENGR 106 needed to be adjusted to make room for the MEAs. Three course topics were dropped in Fall 2003 to provide students more time to focus on and reap the benefits of these open-ended problems.

Finally, developing strategies for assessing student work on the MEAs is a challenge due to the open-ended nature of the problems. Predetermining the elements of a "good" solution, one that addresses the complexity of the problem, has proven difficult. Also, striking a balance between providing student teams' adequate feedback and setting a reasonable expectation of TA time spent on grading has been an issue. However, adding an assessment component to the MEAs emphasizes that they are a valuable part of the class and important for students' future work rather than just something "extra". In Fall 2003, a grading rubric for each MEA lab component was drafted prior to the TA pilot of the problems. The TAs then provided feedback on the rubric based on their solutions to the MEA.

\section{Conclusion}

The Model Eliciting Activities framework has provided a means of addressing and assessing gender equity in the engineering classroom. The aim has been to provide a learning environment that is tailored to a more diverse population than typical engineering course experiences as they allow students with different backgrounds and values to emerge as talented. Through the research methods presented we hope to ascertain a positive effect on interest and persistence in engineering for all students. Following our first year of study, we have been able to make a 
number of informed changes to improve the implementation of MEAs in a freshman level engineering course that we hope will result in an improved learning experience for our students.

\section{Acknowledgements}

The authors acknowledge the support of the National Science Foundation (Grants HRD0120794; Award Title: DEM/RES: Small Group Mathematical Modeling Approaches to Improved Gender Equity in Engineering (SGMM) Project)

Bibliography

1. National Science Foundation, Division of Science Resources Statistics, Women, Minorities, and Persons with Disabilities in Science and Engineering-2002, Arlington, VA (NSF 03-312) (September 2003).

2. Purdue University, Women in Engineering: B.S. Degrees Conferred. https://engineering.purdue.edu/WIEP/stats/BSconferred.html

3. Lesh, R., Hoover, M. Hole, B., Kelly, A., \& Post, T., "Principles for developing thought-revealing activities for students and teachers," In A. E. Kelly \& R. A. Lesh (Eds.) Handbook of Research Design in Mathematics and Science Education (pp. 591-646). Mahwah, NJ: Lawrence Erlbaum Associates, (2000).

4. Chamberlin, M.T., "Design principles for teacher investigations of student work," Manuscript submitted for publication. (2003).

5. Doerr, H. M. \& English, L., "A modeling perspective on students' mathematical reasoning about data," Journal for Research in Mathematics Education, 34(2), 110-137, (2003).

6. Zawojewski, J., Lesh, R., \& English, L., "A models and modeling perspective on the role of small group learning activities," In R. Lesh \& H. M. Doerr (Eds.), Beyond constructivism: Models and modeling perspectives on mathematics problem solving, learning, and teaching (pp. 337-358). Mahwah, NJ: Lawrence Erlbaum. (2003).

7. Eisenhart, M. A. \& Finkel, E., Women's science: Learning and succeeding from the margins, Chicago: University of Chicago Press (1998).

8. Margolis, J. \& Fisher, A., Unlocking the clubhouse: Women in computing, Cambridge, MA: The MIT Press (2002).

9. Accreditation Board for Engineering and Technology, Criteria for Accrediting Programs in Engineering, Baltimore, MA: ABET, Inc. (2003).

10. Lesh, R., Hoover, M., \& Kelly, A., "Equity, assessment and thinking mathematically: Principles for the design of model-eliciting activities," In I. Wirskzup \& R. Streit (Eds.) Developments in school mathematics education around the world: Volume 3 (pp. 104-130). Reston, VA: National Council of Teachers of Mathematics (1993).

11. Lesh, R. \& Doerr, H. M. (Eds.), Beyond constructivism: Models and modeling perspectives on mathematics teaching, learning, and problem solving, Mahwah, NJ: Lawrence Erlbaum Associates (2003).

12. WebCT Campus Edition: Course Management System. http://www.webct.com/products/viewpage?name=products_campus_edition

13. Seymour, E. \& Hewitt, N. M., Talking about leaving: Why undergraduates leave the sciences, Boulder, CO: Westview Press. (1997).

14. Alha, K., "Using ICT to improve the gender balance in engineering education," European Journal of Engineering Education, 28(2), 215-224, (2003).

15. Patton, M. Q., Qualitative evaluation methods, London: Sage Publications (1980).

16. Grimson, J. "Re-engineering the curriculum for the $21^{\text {st }}$ century," European Journal of Engineering Education, 27(1), 31-37, (2002).

Biographical Information

\section{HEIDI A. DIEFES-DUX}

Heidi Diefes-Dux is an Assistant Professor of Freshman Engineering at Purdue University with a joint appointment in the Department of Agricultural and Biological Engineering (ABE). She is the recipient of the Best Teacher Award in Freshman Engineering for the years 2000 and 2002. She received her B.S. and M.S. in Food Science from Cornell University and her Ph.D. from ABE in 1997. 


\section{DEBORAH K. FOLLMAN}

Deborah Follman is an Assistant Professor of Freshman Engineering at Purdue University with a joint appointment in the Department of Chemical Engineering. She received a B.S. in Chemical Engineering from Cornell University in 1994 and a Ph.D. in Chemical Engineering from North Carolina State University in 2000. She was a recipient of the 1999 Apprentice Faculty Grant from the ERM division of ASEE.

\section{P.K. IMBRIE}

P.K. Imbrie is an assistant professor in the department of Freshman Engineering at Purdue University. He received his B.S. and M.S. and Ph.D degree in Aerospace Engineering from Texas A\&M University. His research interests include, educational research, solid mechanics, experimental mechanics, nonlinear materials characterization, microstructural evaluation of materials, and experiment and instrument design.

\section{JUDITH ZAWOJEWSKI}

Judith Zawojewski is an Associate Professor of Mathematics and Science Education at Illinois Institute of Technology with an adjunct faculty appointment to the Department of Curriculum and Instruction at Purdue University. She received a B.S.Ed. in Mathematics and Education at Northwestern University in 1973, a M.S.Ed in Mathematics Education from National College of Education, and a Ph.D. in Education at Northwestern University.

\section{BRENDA CAPOBIANCO}

Brenda Capobianco is an Assistant Professor of Science Education. She received her B.S. in Biology from the University of Alaska-Fairbanks, M.S. in General Science at Central Connecticut State University, and an Ed.D. in Teacher Education and School Improvement at the University of Massachusetts Amherst. Her research interests include issues of gender equity and teacher action research in science and science education.

\section{MARGRET HJALMARSON}

Margret Hjalmarson is a doctoral student in Mathematics Education in the Department of Curriculum and Instruction at Purdue University. She received an M.S. in Mathematics from Purdue University in 2000 and a B.A. in Mathematics from Mount Holyoke College in 1998. 